\title{
Gestão democrática do ensino público em Rio das Ostras (RJ): avanços e retrocessos
}

\section{Democratic management of public education in Rio das Ostras (RJ): advances and setbacks \\ Gestión democrática de la educación pública en Rio das Ostras (RJ): avances y retrocesos}

\author{
ALZIRA BATALHA ALCÂNTARA \\ ORCID iD: http://orcid.org/0000-0001-9597-282X \\ Universidade Estadual do Rio de Janeiro e Universidade Estácio de Sá. \\ MARCIA LISBOA PFEIL \\ ORCID iD: http://orcid.org/0000-0002-1805-8003 \\ Rede municipal de educação de Rio das Ostras, Rio de Janeiro.
}

\begin{abstract}
Resumo: O artigo, fundamentado em pesquisa bibliográfica e documental, investigou as bases normativas institucionais da gestão democrática em Rio das Ostras, município do estado do Rio de Janeiro. A Lei Orgânica explicita a gestão democrática, tendo a participação e a eleição de diretor como pontos centrais. Contudo, as leis que criaram o sistema e o plano municipal não preveem eleição, pautando a gestão sob um viés gerencialista. Conclui-se que, em Rio das Ostras, houve um enfraquecimento da gestão democrática, sobretudo nos mecanismos que deveriam promover a participação.
\end{abstract}

Palavras-chave: Gestão democrática; Rio das Ostras; Eleição.

Abstract: This article, based on bibliographical and documentary research, investigated the institutional normative bases of democratic management in Rio das Ostras, a municipality of the state of Rio de Janeiro. The Organic Law highlight the democratic management, having the participation and the election of a director as central points. However, the laws that created the system and the municipal plan do not foresee election, guiding management under a managerialist bias. It is concluded that there was a weakening of democratic management in Rio das Ostras, especially in the mechanisms that should promote participation.

Keywords: Democratic management. Rio das Ostras. Election.

Resumen: El artículo, fundamentado en investigación bibliográfica y documental, investigó las bases normativas institucionales de la gestión democrática en Rio das Ostras, municipio del estado de Rio de Janeiro. La Ley Orgánica explicita la gestión democrática, teniendo la participación y la elección de director como puntos centrales. Sin embargo, las leyes que crearon el sistema y el plan municipal no prevean elección, pautando la gestión bajo un sesgo gerencialista. Se concluye que, en Rio das Ostras, bubo un debilitamiento de la gestión democrática, sobre todo en los mecanismos que deberian promover la participación.

Palabras clave: Gestión democrática; Rio das Ostras; Elección. 


\section{INTRODUÇÃO}

Este estudo integra a Rede Mapa, pesquisa de âmbito nacional sob coordenação geral do prof. Elton Luiz Nardi, que objetiva estudar a gestão democrática do ensino público, por meio do mapeamento das bases normativas e das condições político-institucionais dos sistemas municipais de ensino. A pesquisa norteia-se nas mesorregiões geográficas definidas pelo Instituto Brasileiro de Geografia e Estatística (IBGE). Atualmente, a Rede Mapa é formada por pesquisadores de dez universidades abarcando oito estados brasileiros: Ceará, Maranhão, Paraná, Piauí, Rio de Janeiro, Rio Grande do Sul, Santa Catarina e Tocantins.

Este artigo, de cunho qualitativo, consubstancia-se em análise bibliográfica e documental, com aporte teórico no materialismo histórico dialético. Buscou contribuir para o debate sobre a gestão democrática e resulta de um subprojeto no âmbito do estado do Rio de Janeiro, coordenado pela profa. Alzira Batalha Alcântara, alcançando os municípios das baixadas litorâneas do estado do Rio de Janeiro. Essa mesorregião compreende dez municípios, apresentados no mapa 1, que se divide em duas microrregiões: a) Bacia de São João: Casimiro de Abreu, Rio das Ostras e Silva Jardim; e b) Região dos Lagos: Araruama, Armação dos Búzios, Arraial do Cabo, Cabo Frio, Iguaba Grande, São Pedro da Aldeia e Saquarema. Vale observar que todos os municípios da mesorregião em tela instituíram os seus respectivos sistemas de ensino.

\section{Mapa 1 - Mesorregião das baixadas litorâneas do estado do Rio de Janeiro.}

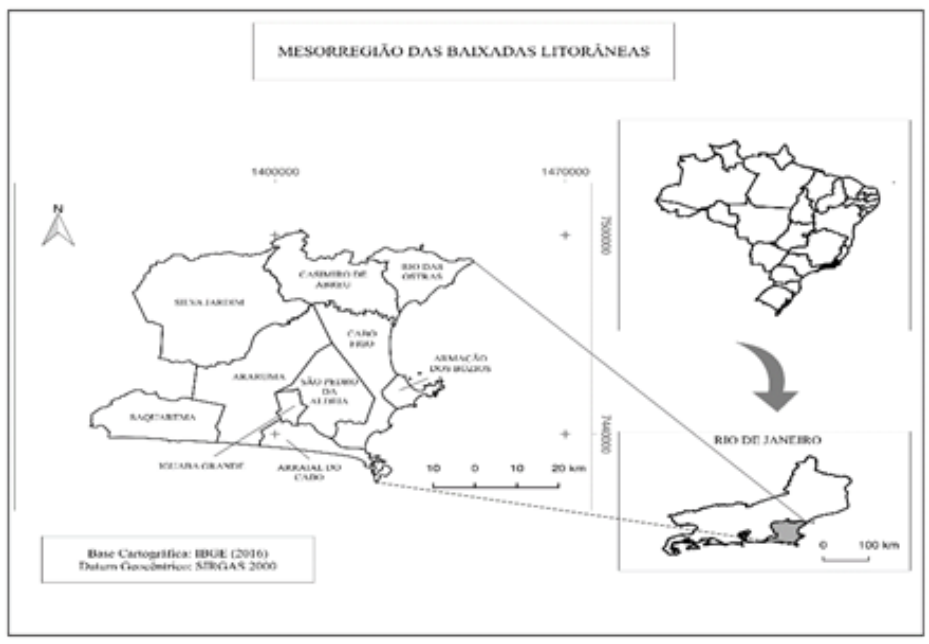

Fonte: IBGE, 1990 
Esta pesquisa focou exclusivamente o sistema municipal de ensino de Rio das Ostras (mapa 2) e objetivou investigar a gestão democrática desse município, a partir das bases normativas institucionais no período de 1994 até 2017, tendo como objetos de análise a Lei Orgânica Municipal (LOM), os marcos legais que instituíram o sistema de ensino e o Plano Municipal de Educação. Para tanto, o artigo, além da parte introdutória e considerações finais, tem quatro seções. A primeira apresenta uma retrospectiva histórica de Rio das Ostras, ressaltando os ganhos obtidos com o processo de emancipação desse município ocorrido em 1992; na segunda seção é debatido o conceito de gestão/administração no capitalismo, para, em seguida, discutir o sentido atribuído à gestão democrática nos marcos legais da sociedade brasileira a partir da Constituição Federal e, por último, retoma-se a gestão democrática no âmbito do município de Rio das Ostras, indicando suas idas e vindas.

\section{RIO DAS OSTRAS: RETROSPECTIVA HISTÓRICA}

Rio das Ostras, município da região das baixadas litorâneas do estado do Rio de Janeiro, configurava-se como um povoado que integrava o distrito Barra de São João, do qual foi desmembrado em $1970^{1}$ se constituindo como um distrito de mesma denominação e subordinado ao município de Casimiro de Abreu. Entre os anos 1991 e 1992 passou por um processo de emancipação, desmembrando-se oficialmente de Casimiro de Abreu em 1992².

1 Decreto-lei n. ${ }^{\circ} 225$ de 01-03- 1970

2 Lei Estadual n. ${ }^{\circ}$ 1.984, de 10-04-1992. 


\section{Mapa 2 - Rio das Ostras.}

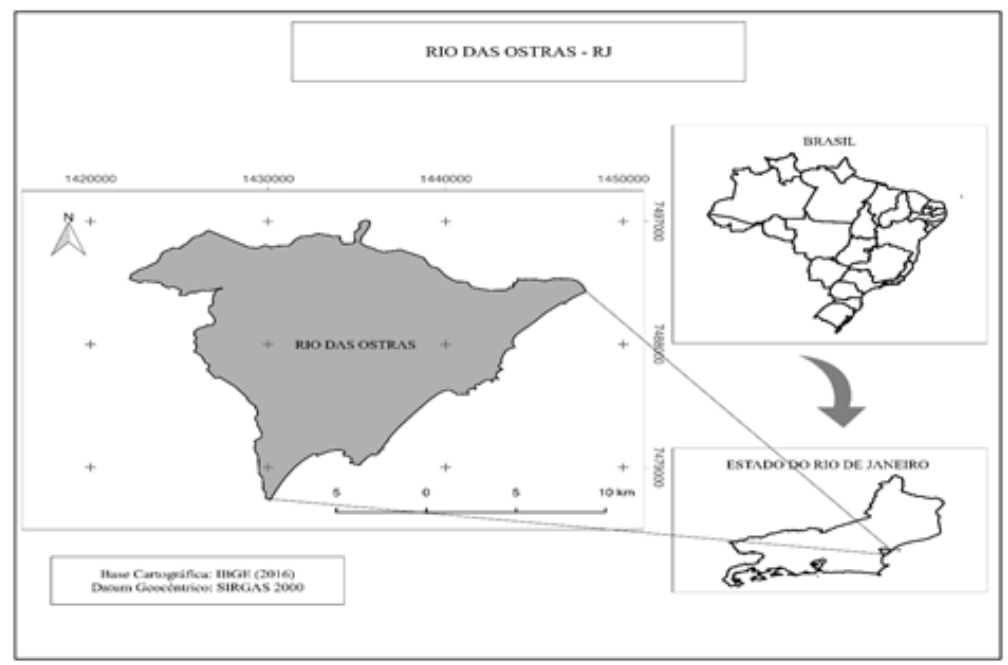

Fonte: IBGE (2016)

A Constituição Federal (CF) de 1988 buscou superar o autoritarismo por meio da descentralização, traduzida, também, no processo de municipalização. A organização político-administrativa da República Federativa do Brasil está expressa no artigo 18, que prevê "a União, os Estados, o Distrito Federal e os Municípios, todos autônomos, nos termos desta Constituição" (BRASIL, 1988). Portanto, como enfatiza Abrucio, (2010, p. 46) o "Brasil se tornou uma das pouquíssimas federações no mundo a dar status de ente federativo aos municípios", tendo como pressuposto legal o compartilhamento do poder juntamente com a manutenção de uma unidade central, bases expressas no regime colaborativo contido no artigo 211, da CF (BRASIL, 1988).

Noâmbito do processo histórico da redemocratização e da descentralização político-administrativo e financeiro proporcionadas pela Carta de 1988, vários municípios foram criados ao longo da década de 1990. A emancipação de Rio das Ostras, em 1992, trouxe para o município recursos da exploração do petróleo, por conta de participação especial prevista e regulamentada pela Lei $n^{\circ} 9.478$, de 6 de agosto de $1997^{3}$, sancionada pelo presidente Fernando Henrique Cardoso, o que implicou, por um lado, a elevação dos níveis de arrecadação dos royalties pelos municípios, e, por outro, a perda do monopólio da exploração e do refino de petróleo no Brasil pela Petrobrás (BRASIL, 1997). 
Esta participação especial expressa no artigo 50 da referida lei e, posteriormente, regulamentada pelo Decreto $\mathrm{n}^{\circ}$ 2.705, de agosto de 1998, implica a compensação financeira relacionada aos concessionários que exploram e/ou produzem petróleo e/ou gás natural (BRASIL, 1997). Juntamente com Armação dos Búzios, Cabo Frio e Casimiro de Abreu, Rio das Ostras destacase no que se refere às atividades ligadas ao petróleo, pois pertence à principal zona de produção petrolífera do Brasil: a Bacia de Campos. Nesse contexto, além dos municípios citados, toda a região ganhou projeção, atraindo novos empreendimentos, aumentando as receitas e as taxas de crescimento populacional. Apesar de as atividades de exploração do petróleo antecederem a década de 1990, foi a partir desse período que a mesorregião das baixadas litorâneas destacou-se nacionalmente. De acordo com Morais (2010, p. 252), as atividades petrolíferas representaram um "motor propulsor da economia regional", assumindo um papel central no que se refere aos índices econômicos fluminenses.

Atualmente, o município de Rio das Ostras conta com um território de $230.621 \mathrm{~km}^{2}$. No último censo, em 2010, a população foi de 105.676 pessoas, mas, a estimativa do IBGE, do ano de 2018, aponta um grande crescimento totalizando 145.989 pessoas no município. No indicador PIB per capita, que é o produto interno bruto, obtido pela divisão da renda municipal pelo seu número de habitantes, Rio das Ostras obteve o segundo maior índice da região, como expresso no gráfico. Os quatro melhores índices pertencem a municípios que integram a Bacia de Campos (Armação dos Búzios, Rio das Ostras, Cabo Frio e Casimiro de Abreu), os quais se sobressaem economicamente nas atividades relacionadas à exploração do petróleo (IBGE, 2010; 2016).

\section{Gráfico $\mathrm{n}^{\circ}$ 1: PIB da mesorregião das baixadas litorâneas do estado do Rio de Janeiro}

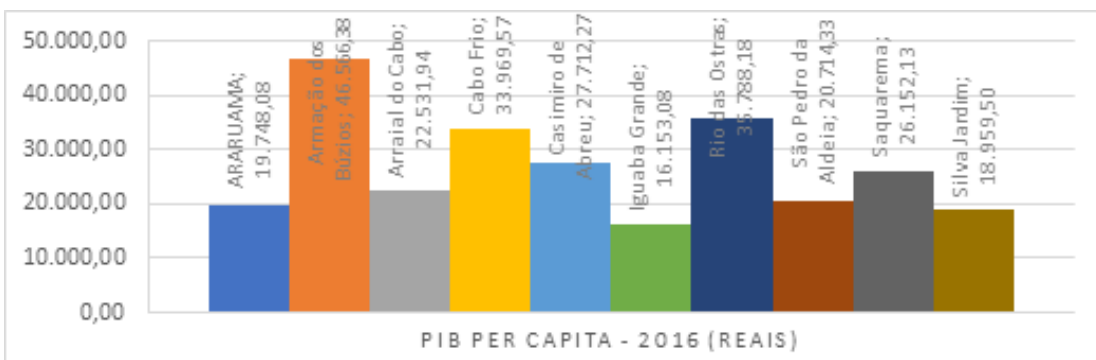

Fonte: Elaborado pelas autoras, a partir dos dados de IBGE (2016) 
Nesse cenário, Rio das Ostras obteve repasses governamentais provenientes dos royalties e das participações especiais que impactaram positivamente no orçamento municipal abrindo possibilidades para a construção de uma infraestrutura adequada, incluindo as demandas relativas aos serviços públicos. Esses recursos materiais proporcionaram condições para a construção de autonomia no campo econômico. Um ano após a lei do petróleo, em 1998, o legislativo municipal propôs a elaboração de um orçamento participativo, o que possibilitou várias experiências envolvendo diferentes setores da sociedade civil.

A administração municipal foi responsável pela regulamentação do Programa de Planejamento e Orçamento Participativo (OP) e pela criação do Conselho Municipal de Planejamento e Orçamento Participativo, instituído pela Lei $n^{\circ} 780 / 2003$, de acordo com os artigos 167 a 169 da Lei Orgânica Municipal. O Conselho Municipal de Planejamento e Orçamento Participativo atua na definição do regulamento do OP. Constituído por membros da sociedade civil e do poder público, esse Conselho é um órgão consultivo da administração pública municipal, o que se traduz em funções como planejar, sugerir e negociar demandas de setores da sociedade civil, contribuindo para definição das prioridades na legislação orçamentária. O órgão executor do OP é a Secretaria Municipal de Planejamento - SECPLAN, atual Secretaria Municipal de Gestão Pública SEGEP (RIO DAS OSTRAS, 2019).

O orçamento participativo, no munícipio em tela, é apresentado como meio para viabilizar e organizar as sugestões indicadas pelos cidadãos. Tal processo visa também informar à sociedade sobre o orçamento público, configurandose, portanto, como ferramenta pedagógica que pretende esclarecer à população acerca do funcionamento da administração, dando transparência às decisões do governo com o objetivo de melhorar a gestão pública. Com a institucionalização do orçamento participativo, criam-se, a um só tempo, condições de participação, ampliação de espaços democráticos e de controle social. Ainda que as demandas da população não sejam atendidas na totalidade, o orçamento participativo se mostra como um espaço de reivindicação, luta e possibilidade de enfrentamento. Essa dinâmica fortalece o processo de participação que contribui para sedimentar uma cultura democrática. 


\section{GESTÃO NO CAPITALISMO: CONCEPÇÕES, EMBATES E POSSIBILIDADES}

A gestão/administração, conforme Paro (2012, p. 25), é a "utilização racional de recursos para a realização de fins determinados". Esse sentido de gestão/administração, proposto pelo autor, enquanto modelo de abstração, busca explicitar seus elementos gerais, referindo-se à constituição do termo com o fito de captar o que é específico na gestão, comum a todas as estruturas sociais.

A gestão /administração, nesse sentido geral, é uma atividade humana necessária para atingir objetivos recorrendo a organização de meios para alcançar fins. Isto é, intenta utilizar os recursos disponíveis racionalmente e considerar o que é mais adequado às finalidades (PARO, 2012). O autor, utilizando-se destas abstrações, buscou identificar os elementos que são determinados historicamente, configurando-se como particulares, em um determinado modo de produção. Tendo no horizonte uma perspectiva de transformação social, tal percepção poderá possibilitar a identificação do que necessita ser modificado, e, assim, conduzir a gestão a serviço de propósitos não autoritários.

As considerações a respeito dos objetivos, dos meios e fins e da racionalidade na gestão serão diferentes em cada estrutura. Souza Filho e Gurgel (2016, p. 28) consideram que quando a gestão se estabelece, se "impregna de elementos histórico-concretos materiais e ídeo-culturais". Assim, a caracterização geral atribuída inicialmente passa a revelar seus elementos sócio históricos. Ou seja, a gestão estará incutida da estrutura econômica e cultural e das relações sociais existentes. Não se aplicaria a abstração inicial de uma gestão geral e, sim, uma gestão "real", historicamente constituída.

Essa determinação histórica da gestão, no contexto de uma sociedade de classes, leva a algumas considerações quanto a sua concretude. Para pensar a gestão no capitalismo, considerou-se, inicialmente, o trabalho como "um processo entre homem e natureza" (MARX, 2015 p. 255), em que o homem se apropria da matéria fornecida pela natureza e a utiliza de maneira mais adequada aos seus objetivos. Esse processo diferencia-se da apropriação de meios naturais pelos animais, na medida em que o ser humano, com sua capacidade de abstração, prevê os possíveis resultados da utilização dos recursos (MARX, 2015). O homem se faz ser histórico transcendendo o natural por meio do trabalho, pois o que é produzido por ele modifica seu próprio meio.

Segundo Paro (2012, p. 38), "O homem é ao mesmo tempo natureza (domínio da necessidade) e negação da natureza (domínio da liberdade)". A liberdade é entendida como oposição à espontaneidade; como algo forjado pelo 
homem no processo de construção da sua humanidade. O homem deseja algo além do que a natureza oferta. Ele deseja e cria o supérfluo e esse processo de querer e criar o liberta das determinações naturais (MENDES, 2013).

Ao transcender o natural, a espécie humana busca, por meio da racionalidade e do trabalho, alcançar objetivos, combinando o emprego de expedientes e ações com o mínimo de tempo e recursos. Tais recursos assumem um caráter material e conceitual, englobando as relações entre os homens e destes com a natureza (PARO, 2012).

Questões relacionadas à utilização racional dos recursos não se aplicariam à vida animal, que se localiza no âmbito da necessidade. As realizações dos animais são predeterminadas pela própria natureza, diferenciando-se para cada espécie, mas imutável em cada uma. A raça humana domina e se diferencia da natureza, utilizando-se de recursos materiais, naturais e/ou conceituais. Os recursos humanos são considerados como aquilo que é inerente ao homem, pois "só este é capaz de criar novas técnicas, produzir novos conhecimentos e acumulá-los historicamente" (PARO, 2012, p. 33).

As relações entre os homens e entre estes e a natureza distinguemse. O trabalho, analisado sob esse aspecto, é um processo em que o homem, com a ajuda de determinados meios, atua modificando o objeto seguindo um fim anteriormente concebido. $\mathrm{O}$ trabalho, como uma atividade que tem por finalidade suprir as necessidades do homem, se qualifica como condição natural da humanidade "comum a todas as formas sociais" (MARX, 2015 p. 261).

A distinção entre o homem e o seu trabalho em relação à natureza só é possível porque ele a modifica e a domina em próprio benefício, produzindo sua existência e perpetuando-se como uma realidade destacada: humana. Reconhecer essa caracterização humana deveria afastar as relações de dominação entre os homens, visto que levaria à perda da própria caracterização do humano e consequente consideração do semelhante como não dotado das mesmas condições, colocando-o na condição de ser dominado como a natureza o é (PARO, 2012).

Ao degradar o semelhante, este é colocado em condição de "coisa", passível de ser dominado e ignora-se o que seria natural entre pares, a cooperação. Esses sujeitos e suas relações pertencem a uma realidade concreta, que leva a uma caracterização específica, inserida em uma forma determinada de sociedade (MARX; ENGELS, 2016). Se entendemos os recursos humanos não como recursos do homem, e sim, o homem como recurso, nos afastamos da abstração inicial da gestão e nos subsumimos na concretude do modo de produção 
capitalista, o que distancia o trabalho de uma condição natural e libertadora do homem. Dessa forma, o trabalho passa a constituir-se como fim e não como meio.

O homem é obrigado a vender sua força de trabalho e realizá-lo para garantir sua sobrevivência (MARX, 2015). Contudo, se, ao abordarmos os recursos da gestão/administração, especificarmos o esforço humano como meio, nos referindo aos sujeitos envolvidos, consideraremos o homem não mais como recurso, mas como fim, sendo ele, portanto, sujeito e não objeto (PARO, 2012).

Todavia, no contexto da estrutura social, o homem é tido como parte indiferenciada da natureza e seu trabalho perde o caráter mediador e, consequentemente, esse processo leva o homem a perder a condição de sujeito, passando ao estado de coisa, dominada por outro homem (PARO, 2012). Esse tratamento do homem pelo homem se deve a condições concretas do modo de produção capitalista. Essas determinações condicionam comportamentos e a "racionalidade" da gestão/administração.

Nessa perspectiva, a adequação dos recursos pressupõe a economia e torna a finalidade elemento determinante na escolha dos meios e das características da racionalidade administrativa, que orientará quais recursos serão utilizados e de que maneira. No modo de produção capitalista, racionalizar o trabalho objetiva o "aumento da eficiência e da produtividade, com vistas a proporcionar maiores e constantes lucros ao proprietário dos meios de produção" (PARO, 2012, p. 77).

$\mathrm{O}$ uso dos recursos, tanto os que são utilizados na relação homemnatureza quanto na relação do homem com seus semelhantes, alcança, a um só tempo, para Souza Filho e Gurgel (2016), as dimensões de produção e reprodução social. O trabalho provém do homem, um ser histórico e social, as condições nas quais se trabalha e a diferença entre os momentos históricos e econômicos são preconizados não pelo "o que" é produzido, mas "como" é produzido e com que "meios de trabalho" (MARX, 2015, p. 257).

A gestão/administração é condicionada pelos seus meios, fins e racionalidade. Em termos concretos, ela determina e é determinada pelos embates sociais, culturais, políticos e econômicos. Tais contradições sociais e a mútua determinação possibilitam uma dimensão progressista da gestão/administração. Paro (2012, p. 43) considera que, apesar de não se configurar como uma "força revolucionária autônoma", suas contradições intrínsecas podem colocá-la como coparticipante da evolução histórica das forças produtivas e das relações de produção.

Em outras palavras, a gestão/administração poderá servir a fins revolucionários ou conservadores. Na sociedade capitalista, ela tem servido para manter e perpetuar o domínio exercido de uma minoria sobre as classes subalternas. 
Todavia, existem possibilidades de a gestão contribuir para a superação da estrutura social vigente, desde que sua dimensão progressista não permaneça no campo da espontaneidade, mas se converta em "práxis reflexivamente revolucionária" (PARO, 2012, p. 44).

\section{GESTÃO DEMOCRÁTICA: MARCOS LEGAIS E RESSIGNIFICAÇÕES}

A gestão democrática da educação foi consignada na Constituição Federal, artigo 206, (BRASIL,1988), mas requer regulamentação por meio de leis complementares. Na década de 1990, foi explicitada na Lei de Diretrizes e Bases da Educação Nacional (LDBEN) (BRASIL, 1996) e, posteriormente, nos Planos Nacionais de Educação (BRASIL, 2001; 2014).

A gestão democrática da educação pública, consagrada como princípio na Constituição Federal (BRASIL, 1988), pode possibilitar meios de participação à sociedade, que fora emudecida por vinte e um anos. Tal fato imprime relevância tanto política quanto acadêmica ao tema. No cenário de lutas pela redemocratização do país, nos anos de 1980, a gestão democrática foi uma das bandeiras que emergiu, juntamente com a descentralização, autonomia e participação. Naquela conjuntura histórica, de maneira simplista, centralização era associada à ditadura, enquanto descentralização à democracia. Contudo, conceitos como autonomia, descentralização e participação foram ressignificados no contexto das reformas políticas, inspiradas pelo ideário neoliberal, ao longo dos anos 1990.

Tais ressignificações, em sintonia com a denominada, no âmbito internacional, Nova Gestão Pública (NGP), incorporam, de um lado, critérios da economia privada para a reforma administrativa do Estado e, por outro, esmaecem a noção de direito, visto que o processo de redemocratização ainda era recente (OLIVEIRA, 2015). De acordo com Nogueira (2011, p.58-59), o reformismo absorveu "quatro ideias inerentes ao discurso democrático em geral e ao radicalismo democrático em particular: descentralização, participação, cidadania e sociedade civil". Tais incorporações atenderam aos argumentos neoliberais "menos Estado, mais democracia, menos burocracia e mais iniciativa", na medida em que houve uma adaptação do vocabulário democrático "à cultura mercantil e a hegemonia". A reforma administrativa do Estado foi divulgada como puramente técnica e não política, tendo, em tese, um objetivo único: o bem-comum. O conceito de descentralização, nesse contexto, foi traduzido como a capacidade de assumir encargos, antes uma responsabilidade das instâncias centrais do Estado. Essa nova lógica elevaria a performance gerencial do setor público (NOGUEIRA, 2011). 
Nessa perspectiva, o Estado intervém minimamente na área social, pois o "bem-estar social pertence à dimensão privada (família, comunidade e mercado)" cabendo ao Estado promover atendimento somente àqueles que não possuem condições próprias de suprir suas necessidades no campo privado (SOUZA FILHO 2006, p.261). O Estado reduz custos na área social, pois o mercado, ao ofertar serviços, passa a ocupar os espaços que, outrora, eram de responsabilidade do Estado. Com essa desresponsabilização, o Estado prioriza concentrar as ações sociais nos grupos que se encontram em situação de pobreza absoluta. Apela-se, segundo Souza Filho (2006, p.262), para a filantropia e para a "solidariedade da sociedade, via voluntariado e parcerias com a sociedade civil" que se apresentam como mecanismos adequados às táticas de intervenção social. Prevê-se a diminuição da presença estatal na área social e executam-se certas estratégias para alcançar objetivos, como: "a redução de gastos sociais - via focalização, descentralização e privatização - e a consequente redução do funcionalismo público" (SOUZA FILHO E GURGEL, 2016, p. 141). Tal concepção define o campo da gestão imbricada aos condicionantes do capitalismo.

Se a reforma, encetada nos anos de 1990, distanciou-se de um Estado provedor e dos princípios democráticos inscritos constitucionalmente, cumpre notar que a eleição, no âmbito federal, do Partido dos Trabalhadores (PT), partido que se opunha às reformas em curso, gerou muitas expectativas. Se programas relevantes voltados para a inclusão social foram efetivados, muitos traços fundantes da gestão anterior, ainda que, por vezes, com matizes diferenciados, permaneceram. Como sinaliza Costa (2019, p. 171), governos do PT não romperam com "aspectos importantes da agenda em curso que levam à privatização da educação, tais como a atuação de instituições não estatais, como ONGs, fundações, institutos, e, mais recentemente, Organizações Sociais, incluindo-se o campo das políticas de avaliação em larga escala". Delineou-se, no dizer de Oliveira (2015), uma política pendular e ambígua. Tal ambiguidade se traduz no campo da gestão educacional por um hibridismo, marcado pela conjugação de princípios democráticos e meritocráticos, como bem expressa, por exemplo, o Plano Nacional de Educação (BRASIL, 2014).

Assim, o projeto político, tecido no alvorecer do século XXI, que se tornou hegemônico, manteve uma administração pautada em pressupostos mercadológicos. Se, por um lado, houve possibilidades de ampliação de mecanismos democráticos via participação e descentralização, por outro, existe um projeto de finalidade mercadológica e gerencialista utilizando-se das mesmas vias. Esse processo se configurou como uma balança de difícil equilíbrio, pois, dependendo da correlação de forças e interesses envolvidos, esboçam-se políticas públicas de cunho mais progressista ou conservador. 


\section{RIO DAS OSTRAS: IDAS E VINDAS}

Setores da sociedade civil se organizaram para emancipação de Rio das Ostras, pois entendiam que, com esse processo, ampliavam-se as possibilidades de assegurar direitos sociais, inclusive no campo educacional. Para tanto, ao longo do tempo, ocorreu uma ação deliberada, intencional, dos sujeitos na construção de um marco legal que favorecesse uma democratização educacional, na sua dupla dimensão: quantitativa e qualitativa. Cumpre notar que, nesse processo emancipatório, Rio das Ostras construiu uma cultura participativa, já expressa na elaboração da Lei Orgânica Municipal, tendo destaque, no âmbito nacional, por conta da construção de um orçamento participativo (RIO DAS OSTRAS, 2019).

Apesar de Rio das Ostras ter instituído seu sistema de ensino por meio do Decreto municipal no 082/1999, tal movimento abriu novos espaços para a participação da sociedade civil e, consequentemente, para o fortalecimento da democracia. Um dos caminhos para essa conquista é a educação, que se formaliza no espaço escolar, inserido nos sistemas de ensino.

Analisa-se a gestão democrática do ensino público no sistema municipal de Rio das Ostras a partir do marco de referências apresentado nas seções anteriores. Constatou-se que a Lei Orgânica Municipal (LOM), promulgada em 1994, previa em seu art.194, \ $2^{\circ}$, a participação da sociedade na eleição direta para o corpo administrativo e direção escolar:

Art. 194 - O Município assegurará gestão democrática de ensino público, na forma da Lei, atendendo as seguintes diretrizes: $\int 2^{\circ}$ - Eleição direta para o Corpo Administrativo e Direção das entidades escolares da rede municipal, com a participação da comunidade escolar.

No entanto, o Decreto municipal n ${ }^{\circ}$ 082/1999, que instituiu o sistema de ensino em Rio das Ostras, sequer cita a gestão democrática, e a lei no 1403/2009, que ratificou a instituição do sistema de ensino e disciplinou a organização do referido sistema, contempla a gestão de forma genérica, mesclando conceitos pautados em concepções distintas: democrática e gerencialista, como consta na seção $\mathrm{I}$, artigo $5^{\circ}, \mathbb{\Omega} 2^{\circ}$ :

As ações da SEMED se pautarão pelos princípios de gestão democrática, produtividade e racionalidade sistêmica, bem como pela autonomia das unidades escolares, priorizando a descentralização das decisões pedagógicas e administrativas. 
Além de utilizar-se de termos gerencialistas, a lei e o decreto em tela não consideram a participação dos professores e da comunidade escolar para a escolha dos diretores, apesar da indicação do art.194, $\$ 2^{\circ}$, da LOM. Da mesma forma, o Plano Municipal de Educação (PME), aprovado em 2015 (lei no 1898/2015), em sintonia com os princípios da Nova Gestão Pública, apresenta aspectos de gestão gerencial, como expressos na estratégia 29.9:

Garantir a participação dos Conselhos Escolares nas discussões sobre nomeações para as funções de Diretor e Diretor Adjunto das Unidades Escolares, que serão exercidas por profissionais indicados pela SEMED, considerando critérios de mérito e desempenho, bem como a participação da comunidade escolar, através de consulta pública, sempre que possível (RIO DAS OSTRAS, 2015, grifo nosso).

Tais determinações opõem-se à LOM (RIO DAS OSTRAS, 1994), visto que a Lei Orgânica prescreve eleição direta para o corpo administrativo e direção das entidades escolares da rede municipal com participação da comunidade escolar. Entretanto, no PME, em simetria ao Plano Nacional de Educação (PNE) (BRASIL, 2014), a escolha do diretor está embasada em critérios de mérito e desempenho, porém a consulta à comunidade escolar, no Plano Municipal, é diluída se comparada ao PNE. No Plano Nacional, a gestão democrática está associada a critérios de mérito, desempenho e consulta à comunidade escolar, enquanto, no Plano Municipal, a consulta ocorrerá "sempre que possível", expressando, portanto, que poderá não haver consulta alguma. Ademais, os Conselhos Escolares participam das discussões, porém a indicação é feita pela Secretaria de Educação, não havendo garantia de que a voz desses Conselhos seja um critério de escolha. Afinal, o grau de participação não ocorre em um campo asséptico. Ou seja, dependerá da correlação de forças entre os setores organizados da sociedade civil, do legislativo e da equipe gestora da política municipal.

Vale notar que o legislativo municipal foi e é marcado por disputas intensas, com o predomínio de setores conservadores. Tais embates se expressam, com raras exceções, pela alta rotatividade de partido político, fato que pode ser atestado no sítio eletrônico da Câmara Municipal (https:/ / www.riodasostras.ri.leg. br/processo-legislativo/legislaturas) que apresenta os membros das legislaturas desde 1993 e respectivos partidos políticos, sendo recorrente a indefinição de partido.

A dissonância entre a Lei Orgânica e o plano municipal ocasionou contestações. Nesse ambiente de disputa, a LOM é alterada dois anos após a publicação do PME de Rio das Ostras. Revogou-se a eleição direta para diretores e corpo administrativo: 
EMENTA: Altera a redação do inciso VI do artigo 84 e revoga o \ $2^{\circ}$ do art. 194 da Lei Orgânica do Município.

A Câmara Municipal de Rio das Ostras, Estado do Rio de Janeiro, nos termos art. 48 da Lei Orgânica do Município, promulga a seguinte Emenda ao texto Legal:

Art. $1^{\circ}$. - O Inciso VI do art. 84 da Lei Orgânica do Município passa a vigorar com a seguinte redação:

"Art. $84-$

$\mathrm{VI}-[\ldots]$

Art. $2^{\circ}$ - Revoga-se o $₫ 2^{\circ}$ do artigo 194 da Lei Orgânica do Município.

Art. $3^{\circ}$. - Esta Emenda entra em vigor na data de sua publicação.

A respeito da eleição para diretores escolares, cabe notar, como indica Paro, que a eleição é parte necessária e integrante do processo democrático. Contudo, se "desvinculada de outras medidas que transformem radicalmente a estrutura administrativa da escola" (2016, p.123), a eleição de um dirigente escolar não corresponderá a uma gestão democrática. Para Lück (2017), a democratização da escola, quando separada de uma prática participativa plena, pode ficar limitada a legitimação de trocas ou a permanência do poder, sem que se vivencie um processo substancialmente participativo. Segundo Paro (2015, p. 41), no "conceito de direção do senso comum, em que poucos exercem seu comando sobre muitos, que vige em nossos sistemas de ensino", o diretor assume o papel de administrador escolar, zelando "pela adequação de meios a fins" e de coordenador do esforço, e é ele que também ocupa o posto mais alto na hierarquia da escola. Mesmo que a unidade escolar apresente mecanismos de participação na gestão, com atribuições deliberativas ou não, como os conselhos escolares, a responsabilidade última recai sobre o diretor. Portanto, conforme Paro (2015, p. 42), o tratamento dado ao diretor escolar e o que se espera dele é "cada vez mais semelhantes ou idênticos ao modo de considerar o típico diretor da empresa capitalista". Considera-se que o PNE e, por indução, o PME de Rio das Ostras encontram-se mergulhados nesse paradigma.

Nesse quadro legislativo, impôs-se uma concepção gerencialista, que, a um só tempo, fragilizou a cultura democrática e evidenciou diferenças na normatização da gestão democrática do ensino público. Ao investigar o quadro legal municipal, constatou-se que houve um retrocesso do ponto de vista participativo. Na LOM de Rio das Ostras (1994), a relevância da participação consta, de forma explícita, em diferentes setores prevendo Conselhos de natureza distinta e orçamento participativo. Este foi ampliado no ano de 2017, por meio do Programa de Orçamento Participativo online, com o duplo objetivo: (1) possibilitar a participação daqueles que não podem estar presencialmente nas 
reuniões e (2) detalhar as diferentes demandas locais, permitindo à população indicar prioridades de investimentos a serem incluídas no orçamento do município para o ano seguinte.

Após muitas pressões sociais, especialmente dos profissionais da educação, o gabinete do prefeito encaminhou à Câmara um Projeto de Lei que trata da gestão democrática para a rede municipal reestabelecendo eleição para diretores e adjuntos. Eleição que fora prevista na LOM, mas revogada pelas leis subsequentes. Em 25 janeiro de 2019, foi aprovada a Lei no 2.190/19 que dispõe sobre a gestão democrática. Propõe, em seu art. $8^{\circ}$, um processo seletivo em três etapas, a saber: (RIO DAS OSTRAS, 2019).

I - avaliação de conhecimento, de caráter eliminatório, composta por questões objetivas de Língua Portuguesa, Legislação Educacional e Gestão Escolar;

II - apresentação de Plano de Gestão à comunidade escolar, etapa obrigatória, sem caráter eliminatório ou classificatório; e

III - eleição direta nas Unidades Escolares.

Parágrafo Único - Os aprovados na avaliação de conhecimento receberão Certificado Profissional com validade de 03 (três) anos.

A eleição foi aprovada legalmente, porém num contexto em que predomina a concepção gerencialista, conforme bem sinaliza Costa (2019, p.172), "a gestão e o papel de gestores foram redefinidos, e a liderança eficaz com base na competência técnica se sobrepôs à competência política”. Nessa conjuntura, o processo de eleição, valorizado na perspectiva da gestão democrática, foi esmaecido.

\section{CONSIDERAÇÕES FINAIS}

Se a gestão é condicionada pelos seus meios, fins e racionalidade, a concretude da realidade expressa que ela, a um só tempo, determina e é determinada por tensões distintas: de ordem social, cultural, política, econômica, dentre outras. Ou seja, a gestão é construída e reconstruída numa arena repleta de disputas. Em função dos embates e contradições sociais, a gestão terá - ou não uma dimensão progressista, podendo, portanto, servir a fins emancipatórios ou conservadores, como expressa Paro (2012).

Na sociedade capitalista, a gestão, por um lado, tem servido, em geral, para reproduzir valores proclamados pelo mercado e, por outro, é apresentada como um trabalho eminentemente técnico e imparcial. Ao se restringir o trabalho de gestão à dimensão técnica, nega-se a complexidade desse processo. Dentro dessa concepção estreita, a democratização da escola, ao trazer à cena múltiplos sujeitos com interesses distintos, pode ser considerada um empecilho para a consecução 
dos fins almejados. Instrumentos administrativos devem ser adequados ao mercado, à meritocracia, a um mundo supostamente técnico. Busca-se "esvaziar" e deslegitimar a participação e o controle social. Anderson (2017) alerta que a Nova Gestão Pública, calcada na lógica da concorrência, não tem alterado apenas as práticas profissionais dos educadores, mas vem, a um só tempo, reconstruindo suas identidades pessoais e comprometendo a natureza da escola pública. Afinal, esta, ao adentrar no ethos competitivo, na cultura do mercado, passa a excluir tudo e todos que possam comprometer "bons resultados", em detrimento do bem comum.

Para se alcançar uma gestão que vá de encontro a esta lógica, faz-se necessário evidenciar a trama dessa concepção em prol de outra racionalidade. Uma gestão, imbricada na perspectiva da emancipação humana, só é possível por meio de um caminho que aposte na força de uma cultura democrática. Alcançar esse objetivo demanda tempo, organização, vontade política. Para tanto, essa cultura democrática carece de grande esforço do governo e da sociedade civil. O campo legal é fundamental, mas nada ou pouco assegura por si só, se não houver uma cultura participativa, edificada em um processo de embates.

Avançamos na formalização da gestão democrática do ensino público por meio de marcos legais que ampliaram possibilidades participativas, porém não se pode ignorar as tensões políticas, bem como os limites estruturais do próprio capitalismo que põem em risco tais avanços. Afinal, a concretude da história revela que o capital não hesita em elidir por completo princípios éticos e democráticos, se estes atravancam a sua dinâmica. Assim, a gestão democrática, enquanto uma construção histórica, depende de mobilização, do grau de organização e da correlação de forças sociais. Tal travessia deve estar alicerçada, como sinaliza Frigotto (2015, p.825), na "dialética do velho e do novo buscando mudanças, mesmo que dentro da ordem do capital, mas contra essa ordem".

No âmbito local, os marcos legais do campo educacional de Rio das Ostras evidenciam que o processo democrático não é um movimento linear. Muito pelo contrário. Se a LOM prescrevia gestão democrática tendo como diretrizes eleição direta com a participação da comunidade escolar, leis posteriores caminharam em direção distinta. É possível inferir um efeito indutor da política federal sobre o local, tanto na lei que criou o sistema de ensino, quanto no Plano Municipal, aprovado em 2015.

Afinal, se o Plano Nacional (BRASIL, 2014) não faz referência à eleição para diretores, os dirigentes locais não consideraram necessário o cumprimento da lei municipal (LOM), ignorando-a por muitos anos, apesar das reivindicações dos professores, que apontavam a dissonância entre a LOM e o PME. 
O Plano Municipal de Rio das Ostras não prescreve eleição para diretores escolares e apresenta a gestão com elementos pautados numa concepção gerencialista, contrários à Lei Orgânica Municipal (LOM). Por conta dessa dissonância, os embates levaram o legislativo a revogar a eleição da LOM, em 2017. Em 2019, foi aprovada a lei 2190/19 com o intuito de disciplinar a gestão democrática, em especial, efetivar a eleição de diretores com a participação de toda a comunidade. Entretanto, no contexto gerencialista, a eleição perde força diante de critérios meritocráticos, evidenciando a complexidade do jogo político.

A gestão democrática é um "local" de disputa, de mobilização e de participação. Acredita-se que a democratização da sociedade passa pela gestão democrática da educação, porque a democracia requer práticas coletivas participativas. Portanto, faz-se necessário compreender os seus contornos, que se constroem nas relações edificadas em uma sociedade de classes repleta de tensões em distintos campos.

\section{REFERÊNCIAS}

ANDERSON, Gary. Privatizando subjetividades: como a Nova Gestão Pública (NGP) está criando o "novo" profissional da educação. RBPAE, v.33, n.3, p.593626, set./ dez., 2017.

BRASIL. Constituição da República Federativa do Brasil de 1988. Disponível em: <http://www.planalto.gov.br/ccivil_03/Constituicao/Constituicao.htm>. Acesso em: 17 maio, 2017.

BRASIL. Lei $\mathrm{n}^{\circ}$ 10172, de 9 de janeiro de 2001. Aprova o Plano Nacional de Educação e dá outras providências. Disponível em: <http://portal.mec.gov.br/ arquivos/pdf/L10172.pdf>. Acesso em: 17 maio, 2017.

BRASIL. Lei $\mathrm{n}^{\mathbf{0}} \mathbf{1 3 . 0 0 5}$, de 25 de junho de 2014. Aprova o Plano Nacional de Educação (PNE) e dá outras providências. Disponível em: <http://www. observatoriodopne.org.br/uploads/reference/file/439/documento-referencia. pdf > . Acesso em: 17 maio, 2017.

BRASIL. Lei $\mathrm{n}^{\circ} \mathbf{9 . 3 9 4}$, de 20 de dezembro de 1996. Estabelece as diretrizes e bases da educação nacional. Diário Oficial [da] República Federativa do Brasil, Brasília, DF, 23 dez. 1996. Disponível em: <http://www.planalto.gov.br/ ccivil_03/Leis/L9394.htm>. Acesso em: 17 maio, 2017. 
BRASIL. Lei $\mathbf{N}^{\circ}$ 9.478, de 6 de agosto de 1997. Disponível em: http://www. planalto.gov.br/ccivil_03/leis/19478.htm. Acesso em: 17 maio, 2018.

COSTA, Marilda de Oliveira. Contrarreformas, Nova Gestão Pública e relações público-privadas: mapeando conceitos, tendências e influências na educação. RBPAE, v. 35, n.1, p.159-179, jan. / abr., 2019.

FRIGOTTTO, Gaudêncio. Trabalho: Horizonte 2021. Educ. Soc. V.36, n. 132, p.821-826, jul. /set. 2015.

INSTITUTO BRASILEIRO DE GEOGRAFIA E ESTATÍSTICA - IBGE. Censo Populacional 2010. Rio de Janeiro - Rio das Ostras.

INSTITUTO BRASILEIRO DE GEOGRAFIA E ESTATÍSTICA - IBGE. Divisão do Brasil em mesorregiões e microrregiões geográficas. Rio de Janeiro: IBGE, 1990. 112 v. 1. Disponível em: http:// biblioteca.ibge.gov.br/ index.php/biblioteca-catálogo?view $=$ detalhes\& $\mathrm{id}=22269$. Acesse em: maio 2017.

INSTITUTO BRASILEIRO DE GEOGRAFIA E ESTATÍSTICA - IBGE. Economia- PIB per capita 2016. Rio de Janeiro - Rio das Ostras.

MARX, Karl. O Capital - Crítica da economia política. Livro 1: O processo de produção do capital (Coleção Marx e Engels). São Paulo: Boitempo, 2015.

MARX, Karl; ENGELS, Friedrich. A ideologia alemã: Crítica da mais recente filosofia alemã em seus representantes Feuerbach, B. Bauer e Stirner, e do socialismo alemão em seus diferentes profetas. São Paulo: Boitempo, 2016.

MORAIS, Alex Pereira de. Considerações sobre o papel dos royalties e participações especiais de petróleo e gás sobre a economia dos municípios confrontantes com a Bacia de Campos. In: MARAFON, Glaucio José; RIBEIRO, Miguel Angelo (orgs.) Revisitando o Território Fluminense III. Rio de Janeiro: Gramma, 2010. P. 243-273.

NOGUEIRA, Marco Aurélio. Um estado para a sociedade civil: Temas éticos e políticos da Gestão Democrática. 3. ed. São Paulo: Cortez, 2011. 
OLIVEIRA, Adriane. Democratização do processo decisório em municípios beneficiários dos royalties petrolíferos: a experiência de Rio das Ostras. 2008. Dissertação. Centro Federal de Educação Tecnológica de Campos. CEFET, 2008.

OLIVEIRA, Dalila Andrade. Nova Gestão Pública e Governos DemocráticosPopulares: contradições entre a busca de eficiência e ampliação do direito à educação. Educ.Soc., Campinas, v.36, n.132, p.625-646, jul./set., 2015.

PARO, V. Henrique. Administração escolar: introdução crítica. 17.ed. São Paulo: Cortez, 2012.

PARO, V. Henrique. Diretor escolar: educador ou gerente? São Paulo: Editora Cortez, 2015.

PARO, V. Henrique. Gestão Democrática da Escola Pública. 4. ed. São Paulo: Cortez, 2016.

PARO, Vitor Henrique. O Princípio da Gestão Escolar Democrática no Contexto da LDB. In: OLIVEIRA, Romualdo de O.; ADRIÃO, Theresa (org.). Gestão financiamento e direito à educação: análise da LDB e da Constituição Federal. 1. ed. São Paulo: Xamã, 2001. Coleção legislação e política educacional: textos introdutórios.

RIO DAS OSTRAS (RJ). Site Oficial da Prefeitura - 2019. Disponível em: http://www.riodasostras.rj.gov.br. Acesso em: maio de 2019.

RIO DAS OSTRAS. Lei $\mathbf{n}^{\mathbf{0}} 1403$ de 2009. Disciplina a organização do Sistema Municipal de Ensino de Rio das Ostras. 12 dez 2009.

RIO DAS OSTRAS. Lei $\mathbf{n}^{\mathbf{0}} \mathbf{1 8 9 8}$ de junho de 2015. Institui o Plano Municipal de Educação de Rio das Ostras. Disponível em: < https://www.riodasostras. rj.gov.br/wp-content/themes/pmro/download/jornal-oficial/744.pdf > . Acesso em: 7 de setembro, 2018.

RIO DAS OSTRAS. Lei $\mathbf{n}^{\mathbf{0}} \mathbf{2 1 9 0}$, de 2019. Dispõe sobre a gestão democrática e eleição direta para diretores e diretores adjuntos das unidades escolares da rede municipal de ensino de Rio das Ostras. Jornal Oficial, Ed. 1012, de 25 jan. 2019. 
RIO DAS OSTRAS. Decreto Municipal no 082, de 22 de setembro de 1999. Institui o Sistema de Ensino do Município de Rio das Ostras.

RIO DAS OSTRAS. Emenda à Lei Orgânica n $^{\circ}$ 039/2017. Disponível em: <https://www.riodasostras.rj.gov.br/wp-content/themes/pmro/download/ jornal-oficial/874.pdf>. Acesso em: 7 de setembro, 2018.

RIO DAS OSTRAS. Lei Orgânica Municipal. Promulgada em 09 de junho de 1994. Disponível em: https://www.riodasostras.rj.gov.br/wp-content/themes/ $\mathrm{pmro} /$ download/leis-e-codigos/leis/lei-organica-emenda-01-a-35.pdf.

SOUZA FILHO, Rodrigo de. Estado, Burocracia e Patrimonialismo no Desenvolvimento da Administração Pública Brasileira. 2006. Tese. Universidade Federal do Rio de Janeiro: UFRJ, 2006.

SOUZA FILHO, Rodrigo de; GURGEL, Claudio. Gestão democrática e serviço social. São Paulo: Cortez, 2016.

\begin{abstract}
Alzira Batalha Alcântara
Doutorado e Mestrado em Educação pela Universidade Federal Fluminense (UFF). Docente do Programa de Pós-graduação em Educação da Universidade Estácio de Sá (UNESA) na linha de pesquisa Políticas, Gestão e Formação de Educadores (PGFE). Desde 2003, integra o corpo docente da Universidade do Estado do Rio de Janeiro (UERJ), na Faculdade de Educação da Baixada Fluminense (FEBF), Departamento de Ciências e Fundamentos da Educação (DCFE).E-mail: alzirabatalha@hotmail.com

\section{Marcia Lisboa Pfeil}

Mestre em Educação pela Universidade Estácio de Sá (UNESA), integrando a linha de pesquisa Políticas, Gestão e Formação de Educadores (PGFE). Bolsista PROSUP/ CAPES. Licenciatura em Educação Artística (UNIRIO) e Bacharelado em Artes Cênicas (UNIRIO) e Pedagogia (FACIBRA). Professora da educação básica do município de Rio das Ostras (RJ). E-mail: marcialisboapfeil@gmail. com
\end{abstract}

